\title{
Successful Remission of Evans Syndrome Associated with Graves' Disease by Using Propylthiouracil Monotherapy
}

\author{
Takashi Ushiki $^{1,2}$, Masayoshi Masuko ${ }^{3}$, Koji Nikkuni ${ }^{2}$, Jun Terukina-Yoshida ${ }^{2}$, \\ Ayako Momotsu-Nanba ${ }^{2}$, Hiroshi Morikawa ${ }^{4}$, Akio Usami ${ }^{5}$, Ichiro Fuse ${ }^{6}$, Ken Toba ${ }^{1}$, \\ Kazue Takai ${ }^{2}$ and Yoshifusa Aizawa ${ }^{1}$
}

\begin{abstract}
A 46-year-old woman with Graves' disease was admitted for anemia and thrombocytopenia. She had previously been treated with methimazole but she self-discontinued the treatment 6 months prior to admission. She was diagnosed with Evans syndrome associated with Graves' disease and treated with propylthiouracil without corticosteroids, which normalized her thyroglobulin level. Surprisingly, while Evans syndrome is characterized by frequent relapses, this patient has been in remission of Evans syndrome for approximately 4 years. The remission of Evans syndrome associated with Graves' disease in the absence of immunosuppressive therapy suggests that these 2 diseases have a common pathogenetic mechanism.
\end{abstract}

Key words: Evans syndrome, Graves' disease, soluble IL-2 receptor, propylthiouracil

(Intern Med 50: 621-625, 2011)

(DOI: 10.2169/internalmedicine.50.4319)

\section{Introduction}

Evans syndrome is an autoimmune disease characterized by recurrent relapses of autoimmune hemolytic anemia (AIHA) and idiopathic thrombocytopenic purpura (ITP) (1). Because spontaneous remissions are very rare, patients require treatment, which usually consists of corticosteroids or intravenous immunoglobulins $(2,3)$. Cyclosporin therapy, rituximab therapy, or bone marrow transplantation are required in some cases that are refractory to treatment (3).

To date, the etiology of Evans syndrome is unclear. Recently, the findings from several cases of Evans syndrome associated with another autoimmune disease characterized by hyperthyroidism, namely Graves' disease, suggest that these 2 conditions may have a common immunological mechanism (4-7). However, this remains unclear because almost all such patients are treated with antithyroid drugs and immunosuppressive therapies, such as corticosteroids (4).
Here, we report the case of a patient who had Evans syndrome associated with Graves' syndrome and has been in long-term remission after improvement of thyroid function due to propylthiouracil (PTU) monotherapy.

\section{Case Report}

A 46-year-old woman who was diagnosed with Graves' disease 8 years previously was admitted to our hospital with symptoms of anemia, thrombocytopenia, and dyspnea in September 2006. She had been treated with methimazole (MMI) for Graves' disease, but she self-discontinued it 6 months before admission. On the day before admission, she complained of hyperthermia and dyspnea to her doctor. Hematological examination revealed that her hemoglobin concentration was $6.7 \mathrm{~g} / \mathrm{dL}$ and the platelet count was $20.6 \times 10^{4} /$ $\mu \mathrm{L}$. MMI treatment for Graves' disease as well as coagulation disturbance with heparin and warfarin for atrial fibrillation were immediately initiated. The following day, however,

\footnotetext{
${ }^{1}$ Department of Hematology, Niigata University Graduate School of Medical and Dental Sciences, Japan, ${ }^{2}$ Department of Hematology, Niigata City General Hospital, Japan, ${ }^{3}$ Department of Stem Cell Transplantation, Niigata University Medical and Dental General Hospital, Japan, ${ }^{4}$ Department of Endocrinology, Niigata City General Hospital, Japan, ${ }^{5}$ Usami Clinic, Japan and ${ }^{6}$ Bioscience Medical Research Center, Niigata University Medical and Dental General Hospital, Japan

Received for publication August 4, 2010; Accepted for publication December 6, 2010

Correspondence to Dr. Takashi Ushiki, tushiki@med.niigata-u.ac.jp
} 
Table 1. Laboratory Findings on Admission

\begin{tabular}{|c|c|c|c|c|}
\hline WBC & $2500 / \mu \mathrm{L}$ & APTT & \multicolumn{2}{|c|}{58.2 seconds } \\
\hline St & $5.0 \%$ & (Control & \multicolumn{2}{|c|}{33.7 seconds) } \\
\hline Seg & $77.0 \%$ & РТ\% & \multicolumn{2}{|l|}{$57 \%$} \\
\hline Lym & $12.0 \%$ & PT-INR & \multicolumn{2}{|l|}{1.50} \\
\hline Eo & $1.0 \%$ & Fib & \multicolumn{2}{|l|}{$201 \mathrm{mg} / \mathrm{dL}$} \\
\hline $\mathrm{Ba}$ & $2.0 \%$ & FDP & \multicolumn{2}{|l|}{$3.7 \mu \mathrm{g} / \mathrm{mL}$} \\
\hline Mo & $3.0 \%$ & D-Dimer & \multicolumn{2}{|l|}{$1.2 \mu \mathrm{g} / \mathrm{mL}$} \\
\hline $\mathrm{RBC}$ & $3.9 \times 10^{6} / \mu \mathrm{L}$ & ATIII & \multicolumn{2}{|l|}{$52 \%$} \\
\hline $\mathrm{Hb}$ & $7.1 \mathrm{~g} / \mathrm{dL}$ & & & \\
\hline $\mathrm{Ht}$ & $22.3 \%$ & & & \\
\hline MCV & $59.1 \mathrm{fL}$ & \multicolumn{3}{|c|}{ Thyroid Function Test } \\
\hline \multicolumn{5}{|c|}{ Reticulocyte $25 \%$} \\
\hline PIt & $5.2 \times 10^{4} / \mu \mathrm{L}$ & \multirow{4}{*}{$\begin{array}{l}\text { TSH } \\
\text { Free T3 } \\
\text { Free T4 }\end{array}$} & & $<0.01 \mu \mathrm{lU} / \mathrm{mL}$ \\
\hline GOT & $32 \mathrm{IU} / \mathrm{L}$ & & & $20.34 \mathrm{pg} / \mathrm{mL}$ \\
\hline GPT & $20 \mathrm{IU} / \mathrm{L}$ & & & $>8.0 \mathrm{ng} / \mathrm{dL}$ \\
\hline LDH & $196 \mathrm{IU} / \mathrm{L}$ & & & \\
\hline ALP & $478 \mathrm{IU} / \mathrm{L}$ & \multirow{2}{*}{\multicolumn{3}{|c|}{$\begin{array}{l}\text { TSH Recepter Antibody } 17.4 \mathrm{IU} / \mathrm{mL} \\
\text { Antithyroglobulin Antibody } 57.0 \mathrm{U} / \mathrm{mL}\end{array}$}} \\
\hline T-Bil & $2.5 \mathrm{mg} / \mathrm{dL}$ & & & \\
\hline D-Bil & $1.0 \mathrm{mg} / \mathrm{dL}$ & & & \\
\hline ChE & $47 \mathrm{IU} / \mathrm{L}$ & & & \\
\hline $\mathrm{Fe}$ & $8 \mu \mathrm{g} / \mathrm{dL}$ & & & \\
\hline Ferritin & $24.7 \mathrm{ng} / \mathrm{mL}$ & & & \\
\hline CRP & $0.43 \mathrm{mg} / \mathrm{dL}$ & & & \\
\hline
\end{tabular}

her hemoglobin level and platelet count decreased to $6.2 \mathrm{~g} /$ $\mathrm{dL}$ and $6.8 \times 10^{4} / \mu \mathrm{L}$, respectively. A chest radiograph obtained at that time showed cardiomegaly and a lung infiltrate. She was transferred to our hospital on the second day after hospitalization.

Physical examination revealed the following results: pulse rate, 100 beats/min (with atrial fibrillation); blood pressure, $138 / 66 \mathrm{mmHg}$; and body temperature, $37.2^{\circ} \mathrm{C}$. The palpebral conjunctiva was anemic, and the bulbar conjunctiva was not icteric. A large goiter without nodules was found. Although the cardiac examination yielded normal results, jugular venous distension was observed. On auscultation, moist rales were heard in both the lower lung fields. Her liver, spleen, and superficial lymph nodes were not palpable, and her distal extremities had many petechiae and were edematous.

The patient's initial hemoglobin level and mean corpuscular volume were $7.1 \mathrm{~g} / \mathrm{dL}$ and $59.1 \mathrm{fL}$, respectively. The platelet count was $5.2 \times 10^{4} / \mu \mathrm{L}$, and the reticulocyte count was $25 \%$. A direct Coombs test was weakly positive, and the warm reactive antibody for AIHA was an immunoglobulin $\mathrm{G}(\mathrm{IgG})$ antibody. The haptoglobin type 2-2 level was 69 $\mathrm{mg} / \mathrm{dL}$, which is at the lower limit of the normal range. The serum iron and ferritin levels were $8 \mu \mathrm{g} / \mathrm{dL}$ and $24.7 \mathrm{ng} / \mathrm{mL}$, respectively. The platelet-associated IgG (PA-IgG) level was $67.1 \mathrm{ng} / 10^{7}$ cells, and the lactate dehydrogenase level was $196 \mathrm{IU} / \mathrm{L}$. The total bilirubin and direct bilirubin levels were $2.5 \mathrm{mg} / \mathrm{dL}$ and $1.0 \mathrm{mg} / \mathrm{dL}$, respectively, indicating hyperbilirubinemia. A bone marrow biopsy revealed a normocellular marrow and markedly increased number of megakaryocytes with no dysplastic changes. In addition, there was slight erythroid hyperplasia, and the myeloid/erythroid (M/ E) ratio was 1.6. A diagnosis of Evans syndrome was made on the basis of a positive Coombs test, hemolytic anemia, and thrombocytopenia with reactive bone marrow changes. In addition, iron-deficiency anemia (IDA) was considered a complication. Furthermore, the thyroid hormone level was elevated, whereas the thyroid-stimulating hormone (TSH) was suppressed. The tests involving antibodies for the TSH receptor (TSHR) and thyroglobulin also yielded positive results. An initial study of the cell subsets revealed a CD4/ CD8 ratio of 2.12. The serum level of soluble interleukin-2 receptor (sIL-2R) was found to be $8,480 \mathrm{U} / \mathrm{mL}$. The brain natriuretic peptide (BNP) level was $682 \mathrm{pg} / \mathrm{mL}$ because of acute heart failure secondary to hyperthyroidism. The coagulation test revealed prolongation of the activated partial thromboplastin time (APTT) and prothrombin time (PT) due to a coagulation disturbance.

On admission, the patient underwent a computed tomography (CT) scan of the chest, which showed diffuse infiltrates in both lungs. Because of the presence of hypoxia and bloody phlegm, we performed an emergency fiberoptic bronchoscopy, which revealed diffuse oozing of blood from all lung segments. The bronchoalveolar lavage fluid did not show any evidence of infection, systemic lupus erythematosus, or antineutrophil cytoplasmic antibody-associated vasculitis. The laboratory data did not reveal any findings indicative of Goodpasture's syndrome. Pulmonary hemorrhage was thought to be due to the coagulation disturbances. Detailed laboratory data are shown in Table 1, 2. In addition, no other chronic bleeding point except pulmonary hemorrhage was found throughout the examination. A whole-body CT scan revealed many swollen paraaortic and mesenteric lymph nodes, approximately $1 \mathrm{~cm}$ in diameter. These swollen nodes diminished within 1 month of antithyroid therapy.

The patient was diagnosed with Evans syndrome associated with Graves' disease. MMI therapy was changed to PTU therapy (300 mg/day) to prevent the drug-induced pancytopenia and to treat Graves' disease. We then treated the coagulation disturbances due to the pulmonary hemorrhage. The bleeding was arrested, and we began ferrotherapy with 
Table 2. Serological Findings

\begin{tabular}{|c|c|c|c|}
\hline & sIL-2R & $8480 \mathrm{U} / \mathrm{mL}$ \\
\hline \multirow{3}{*}{$\begin{array}{l}\text { Coombs Test } \\
\text { Direct } \\
\text { Broad } \\
\text { Anti-IgG }\end{array}$} & $( \pm)$ & VitB12 & $>1500 \mathrm{pg} / \mathrm{mL}$ \\
\hline & $($ weak+) & Folic Acid & $6.7 \mathrm{ng} / \mathrm{mL}$ \\
\hline & (weak+) & & \\
\hline Detachment Test & negative & ANA & 40 index \\
\hline Anti-C3d Ab & $(-)$ & Anti-ds-DNA IgG Ab & $<2.0 \mathrm{IU} / \mathrm{mL}$ \\
\hline Anti-C3d,b Ab & $(-)$ & Anti-Sm Ab & $<7.0 \mathrm{U} / \mathrm{mL}$ \\
\hline Indirect & $(-)$ & $\begin{array}{l}\text { Lupus anticoaggulant } \\
\text { Anti-cardiolipin } \beta 2 \text { GPI Ab }\end{array}$ & $\begin{array}{l}\text { negative } \\
\text { negative }\end{array}$ \\
\hline PA-IgG & $\mathrm{g} / 10^{7}$ cells & $\begin{array}{l}\text { Anti-cardiolipin IgG Ab } \\
\text { Anti-SS-AAb }\end{array}$ & $\begin{array}{l}\text { negative } \\
<7.0 \mathrm{U} / \mathrm{mL}\end{array}$ \\
\hline Haptoglobin & $69 \mathrm{mg} / \mathrm{dL}$ & $\begin{array}{l}\text { Anti-SS-B Ab } \\
\text { MPO-ANCA }\end{array}$ & $\begin{array}{l}<7.0 \mathrm{U} / \mathrm{mL} \\
<10 \mathrm{EU}\end{array}$ \\
\hline \multirow{2}{*}{$\begin{array}{l}\text { Suger Water Tes } \\
\text { Ham Test }\end{array}$} & & PR3-ANCA & $<10 \mathrm{EU}$ \\
\hline & $(-)$ & $\begin{array}{l}\text { Anti-GBM Ab } \\
\text { BNP }\end{array}$ & $\begin{array}{l}<10 \mathrm{EU} \\
682 \mathrm{pg} / \mathrm{mL}\end{array}$ \\
\hline
\end{tabular}

PA-lgG: Platelet-associated IgG, sIL2-R: soluble interleukin-2 recepter, ANA: anti-nuclear antibody, GPI: glycoprotein, MPO-ANCA: myeloperoxidase antineutrophil cytoplasmic antibody, PR3-ANCA: proteinase-3 antineutrophil cytoplasmic antibody, GBM: glomerular basement membrane, BNP: brain natriuretic peptide, $\mathrm{Ab}$ : antibody

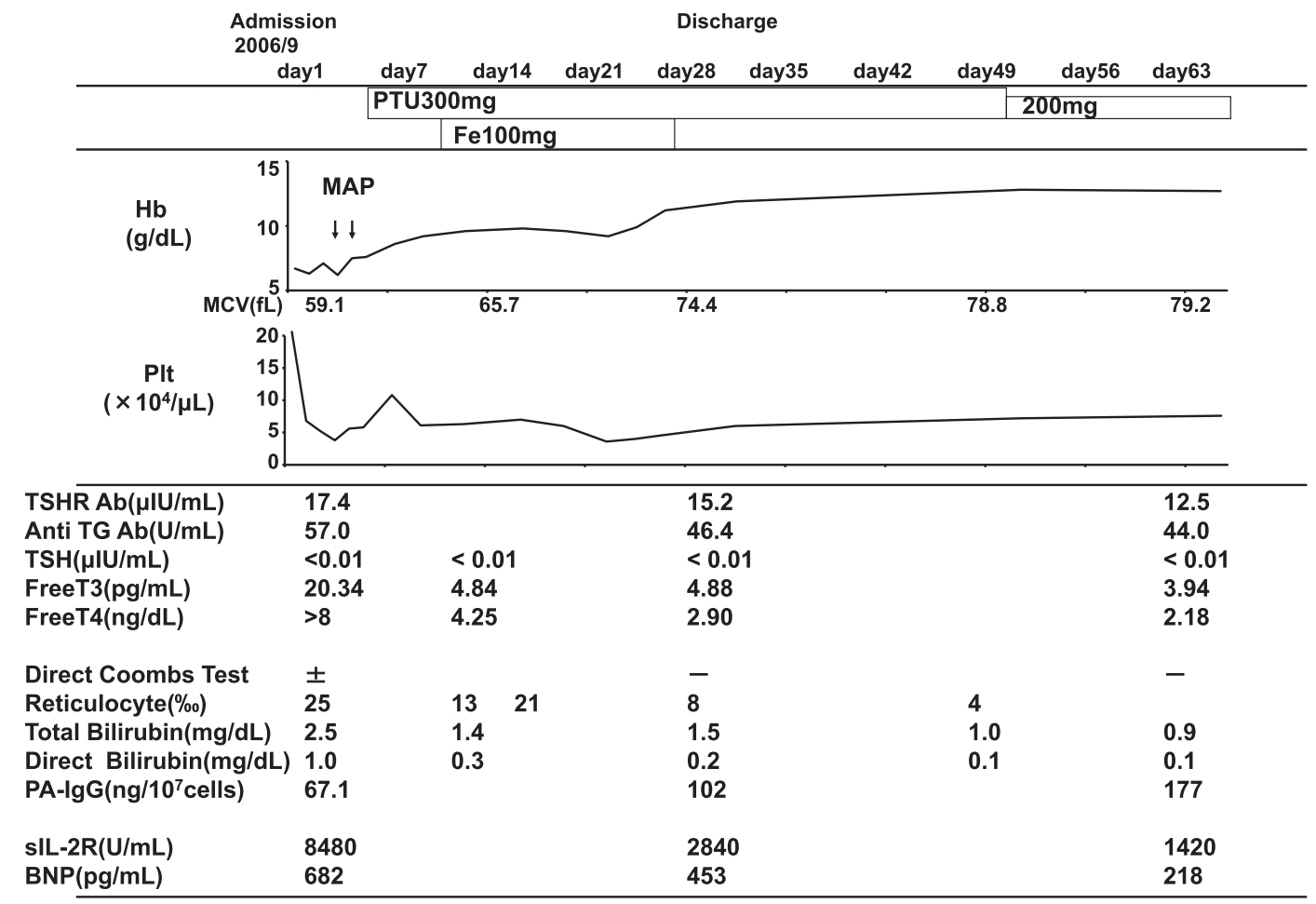

Figure 1. Short-term clinical course of the patient. MAP: red blood cells in mannitol-adeninephosphate, PTU: propylthiouracil, TSHR Ab: TSH receptor antibody, Anti TG Ab: antithyroglobulin antibody

an iron supplement (100 mg/day) for IDA. Surprisingly, when the patient's thyroglobulin level normalized, the direct Coombs test yielded negative results, without corticosteroid treatment (Fig. 1). Moreover, her sIL-2R level decreased with PTU monotherapy alone (Fig. 1). Although her PA-IgG level did not decrease as quickly as did the other measured parameters, her platelet count gradually increased until it was almost normal during long-term observation (Fig. 2). In addition, her BNP level decreased along with the normalization of thyroid function.

The patient has continued PTU therapy for the past 4 years, and we have periodically measured her blood counts and indirect bilirubin levels during this time. Her reticulocyte and bilirubin levels reached the normal range with the normalization of her thyroglobulin function. Her Evans syndrome has been in remission and she has had no relapses to date.

\section{Discussion}

Evans syndrome characteristically presents with a chronic and relapsing clinical course (8) after the first-line immuno- 


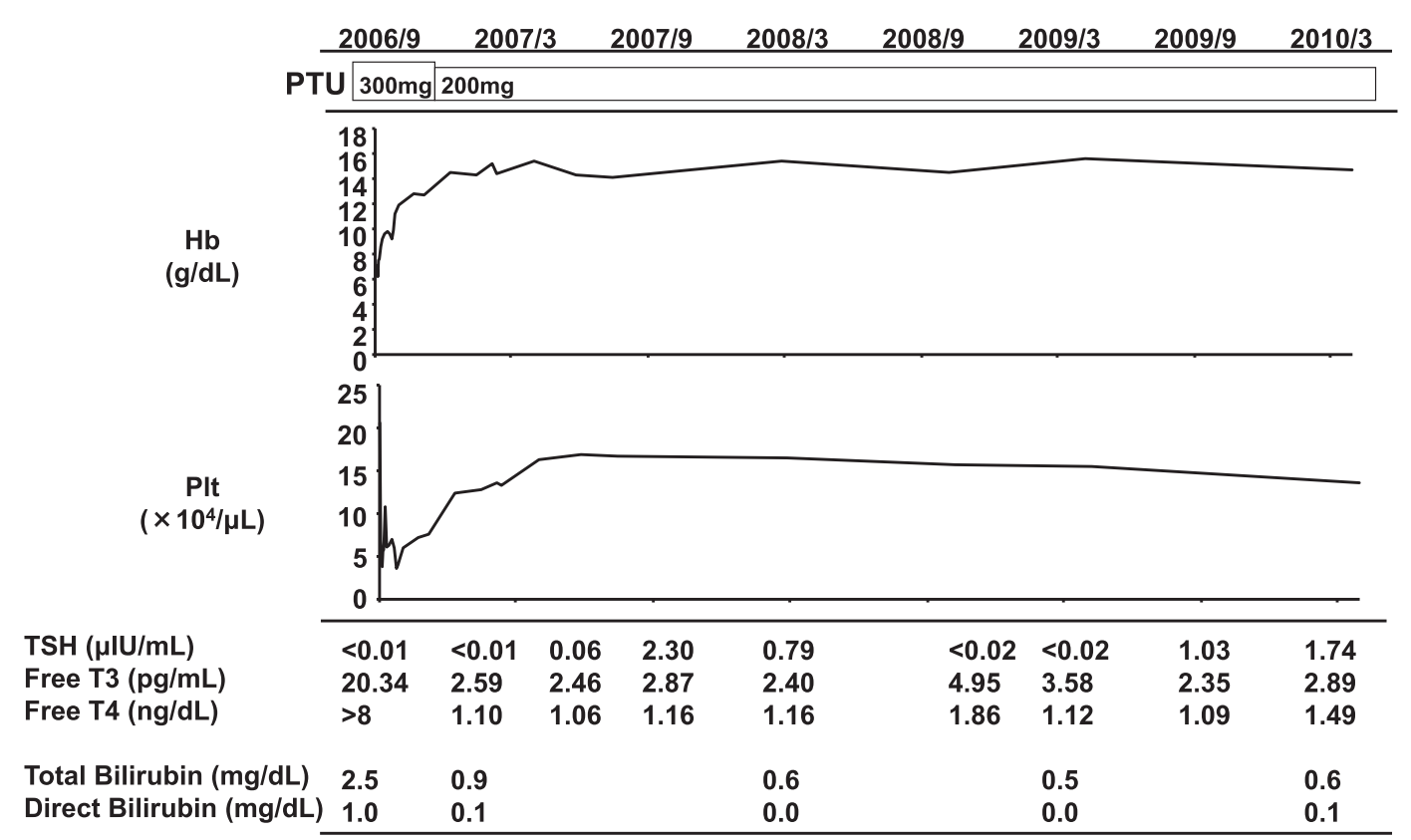

Figure 2. Long-term clinical course of the patient. PTU: propylthiouracil

suppressive therapies (9). Michel et al reported that immunosuppressive therapies could be discontinued in only 22 of 68 patients with Evans syndrome (32\%), after a mean follow-up of 4.8 years (10). Patients with AIHA respond well to steroids, but most remain steroid-dependent and many require second-line treatment (11). Patients with ITP usually require treatment at the time of diagnosis, and only $5-9 \%$ of such patients achieve spontaneous remission (12). Considering these issues, maintaining remission of AIHA and ITP without immunosuppressive therapies is very rare. Therefore, the present case of a patient who had Evans syndrome associated with Graves' syndrome and has been in remission since 4 years after PTU monotherapy is extremely interesting with regard to the pathogenetic mechanisms underlying Evans syndrome.

We diagnosed this patient with Evans syndrome and IDA. The diagnosis of AIHA was based on the following symptoms: 1) low hemoglobin level, 2) reticulocytosis with slight erythroid hyperplasia of the bone marrow, 3) elevated indirect bilirubin level, 4) haptoglobin level at the lower limit of the normal range, and 5) positive results for broad-spectrum Coombs test.

Because of IDA and the mixed pathological conditions, diagnosing AIHA is complicated. However, the present patient's clinical course was different from that exhibited by patients with IDA alone. First, the patient presented with reticulocytosis on admission, which is not normally associated with IDA. Furthermore, slight erythroid hyperplasia was found in the bone marrow aspiration (M/E, 1.6). Second, emergency reticulocytosis will usually occur after ferrotherapy in IDA patients. In the present case, however, the reticulocyte count decreased to the normal range after ferrotherapy without marked reticulocytosis; this is the clinical course of remitted AIHA. Third, the indirect bilirubin level revealed a normal bilirubin range after normalization of the thyroid hormone level, which further suggested the remission of AIHA. Collectively, these parameters strongly suggested that the patient had AIHA, rather than IDA alone.

The symptoms of autoimmune thyroiditis, such as Graves' disease and Hashimoto's thyroiditis, often coincide with organ specific disorders, including pernicious anemia, Addison's disease, type 1 diabetes mellitus, ITP, and AIHA (13). However, the association of Evans syndrome with Graves' disease is rare.

In the present case, the direct Coombs test became negative immediately after starting antithyroid drug treatment due to decreasing levels of autoantibodies and the immunosuppressive effects of PTU. Usually, autoimmune diseases require immunosuppressive therapies in order to enter remission. However, in patients taking antithyroid drugs, but not corticosteroids, serum concentrations of autoantibodies decrease along with normalization of thyroid function (14). TSHR autoantibodies, which are associated with Graves' disease, are oligoclonal $\operatorname{IgG}_{2}$ antibodies (15) that can nonspecifically attach to the surface of red blood cells (16). In this particular case study, since the warm reactive antibody for AIHA was an IgG antibody, it is likely that the TSHR autoantibodies cross-reacted with red blood cells, and decreasing TSHR autoantibodies may have contributed to the remission of AIHA. In addition, recent studies show that antithyroid drug therapy increases the number of circulating suppressor $\mathrm{T}$ cells and decreases the number of helper $\mathrm{T}$ cells and natural killer cells (17). Antithyroid drugs may also induce apoptosis of intrathyroidal lymphocytes (18) and decrease expression of class II human leukocyte antigens (HLA) (19). These results suggest that antithyroid drugs may have had immunosuppressive effects that contribute to remission of not only Graves' disease but also Evans syndrome in this patient. However, further studies are required to elucidate the underlying mechanism. 
In hyperthyroidism, thrombocytopenia is the result of thyroid hormone stimulation of the activated reticuloendothelial system (20). Furthermore, increased blood flow, due to hyperthyroidism, increases phagocytosis in the reticuloendothelial system (21). In the present case, the platelet count temporarily increased after PTU therapy and this normalized thyroid function. Although PTU therapy did not significantly change the patient's PA-IgG level, her platelet count increased in proportion to the normalization of thyroid function. The increased platelet counts with normalization of thyroid hormone were thought to be caused by remission of ITP and the decrease in phagocytosis in the reticuloendothelial system.

Furthermore, the patient's sIL-2R level decreased after antithyroid therapy, which is consistent with the findings by Zwirska-Korczala et al, who reported that sIL-2R levels are increased in patients with Graves' disease and decreased after antithyroid therapy (22). Serum IL-2R levels depend on thyroid function because thyroxine stimulates the release of sIL-2R (22). Patients with AIHA also show high levels of sIL-2R, which indicates the hyperactivation of $\mathrm{CD}^{+}$lymphocytes (23). As a result, sIL-2R is a good biomarker for the state of AIHA.

In conclusion, remission of Evans syndrome without immunosuppressive therapy in this case suggests that Evans syndrome and Graves' disease have a common pathogenetic mechanism. Further studies are required to elucidate the mechanisms underlying Evans syndrome and its association with Graves' disease.

The authors state that they have no Conflict of Interest (COI).

\section{References}

1. Evans RS, Takahashi K, Duane RT, Payne R, Liu C. Primary thrombocytopenic purpura and acquired hemolytic anemia; evidence for a common etiology. AMA Arch Intern Med 87: 48-65, 1951.

2. Dhingra KK, Jain D, Mandal S, Khurana N, Singh T, Gupta N. Evans syndrome: a study of six cases with review of literature. Hematology 13: 356-360, 2008.

3. Norton A, Roberts I. Management of Evans syndrome. Br J Haematol 132: 125-137, 2006.

4. Kuroda H, Kida M, Watanabe H, Matsunaga T, Niitsu Y, Matsumoto M. Basedow disease associated with Evans syndrome. Rinsho Ketsueki 46: 1118-1122, 2005 (in Japanese).

5. Yashiro M, Nagoshi H, Kasuga Y, et al. Evans' syndrome associ- ated with Graves' disease. Intern Med 35: 987-990, 1996.

6. Shimohakamada Y, Fukuda N, Shinohara K, Inoue Y. Simultaneous occurrence of Basedow's disease and autoimmune hemolytic anemia. Rinsho Ketsueki 42: 328-331, 2001 (in Japanese).

7. Ikeda K, Maruyama Y, Yokoyama M, et al. Association of Graves' disease with Evans' syndrome in a patient with IgA nephropathy. Intern Med 40: 1004-1010, 2001.

8. Scaradavou A, Bussel J. Evans syndrome. Results of a pilot study utilizing a multiagent treatment protocol. J Pediatr Hematol Oncol 17: 290-295, 1995.

9. Moyo VM, Smith D, Brodsky I, Crilley P, Jones RJ, Brodsky RA. High-dose cyclophosphamide for refractory autoimmune hemolytic anemia. Blood 100: 704-706, 2002.

10. Michel M, Chanet V, Dechartres A, et al. The spectrum of Evans syndrome in adults: new insight into the disease based on the analysis of 68 cases. Blood 114: 3167-3172, 2009.

11. Lechner K, Jager U. How I treat autoimmune hemolytic anemias in adults. Blood 116: 1831-1838, 2010.

12. Robak T, Robak P. Treatment options for autoimmune cytopenias. Transfus Med Hemother 31: 332-340, 2004.

13. Biro E, Szekanecz Z, Czirjak L, et al. Association of systemic and thyroid autoimmune diseases. Clin Rheumatol 25: 240-245, 2006.

14. McGregor AM, Petersen MM, McLachlan SM, Rooke P, Smith BR, Hall R. Carbimazole and the autoimmune response in Graves' disease. N Engl J Med 303: 302-307, 1980.

15. Michalek K, Morshed SA, Latif R, Davies TF. TSH receptor autoantibodies. Autoimmun Rev 9: 113-116, 2009.

16. Sato A, Zakarija M, McKenzie JM. Characteristics of thyrotropin binding to bovine thyroid plasma membranes and the influence of human IgG. Endocr Res Commun 4: 95-113, 1977.

17. Cooper DS. Antithyroid drugs. N Engl J Med 352: 905-917, 2005.

18. Mitsiades N, Poulaki V, Tseleni-Balafouta S, Chrousos GP, Koutras DA. Fas ligand expression in thyroid follicular cells from patients with thionamide-treated Graves' disease. Thyroid 10: $527-$ 532, 2000.

19. Zantut-Wittmann DE, Tambascia MA, da Silva Trevisan MA, Pinto GA, Vassallo J. Antithyroid drugs inhibit in vivo HLA-DR expression in thyroid follicular cells in Graves' disease. Thyroid 11: 575-580, 2001.

20. Lamberg BA, Kivikangas V, Pelkonen R, Vuopio P. Thrombocytopenia and decreased life-span of thrombocytes in hyperthyroidism. Ann Clin Res 3: 98-102, 1971.

21. Ogihara T, Katoh H, Yoshitake H, Iyori S, Saito I. Hyperthyroidism associated with autoimmune hemolytic anemia and periodic paralysis: a report of a case in which antihyperthyroid therapy alone was effective against hemolysis. Jpn J Med 26: 401-403, 1987.

22. Zwirska-Korczala K, Berdowska A, Jochem J, et al. Influence of thyroxine on serum soluble interleukin-2 receptor alpha levels in thyroid disorders. J Clin Pharm Ther 29: 151-156, 2004.

23. Fagiolo E, Vigevani F, Pozzetto U. High cytokine serum levels in patients with autoimmune hemolytic anemia (AIHA). Immunol Invest 23: 449-456, 1994

(C) 2011 The Japanese Society of Internal Medicine

http://www.naika.or.jp/imindex.html 